\title{
Identifikasi Nilai Etnosains pada Kearifan Lokal Berkarang dan Menyondong Ikan Pada Masyarakat Pesisir Bintan
}

\author{
Bony $\operatorname{Irawan}^{1^{*},}$ Erda Muhartati ${ }^{2}$, \\ ${ }^{1,2,)}$ Program Studi Pendidikan Biologi, Fakultas Keguruan dan Ilmu Pendidikan, Universitas Maritim Raja Ali Haji, \\ Tanjungpinang, Indonesia
}

Pengiriman: 3 Oktober 2019; Diterima: 20 Oktober 2019; Publikasi: Oktober 2019

\begin{abstract}
This studi aimed to identify ethnoscience value contained in traditional activity of coastal society in Bintan called menyondong and berkarang. Menyondong is an activity to catch fish and sea produces by using handheld net (tangguk). Menyondong is usually performed late at afternoon until dusk or maghrib by walking in the shallow water along a parallel line to the coastline. Berkarang is an activity to collect the sea produces stranded in the intertidal area during the time of low tide. Both activity has an economic value as well as as ethnoscience value behind it. This ethnographic study is conducted through series of observations in popular spots for berkarang. Additional data were acquired through interviews. The study concluded that there are ethnoscience values contained in menyondong and berkarang, such as local names and understandings about the species collected, in the form of procedures followed in these activities, and in the knowledge timing to conduct the activities.
\end{abstract}

Keywords: Ethnoscience,Local Wisdom, Menyondong, Berkarang, Bintan,

ABSTRAK: Penelitian ini bertujuan untuk mengidentifikasi nilai etnosains dalam aktivitas menyondong dan berkarang. Menyondong adalah kegiatan menangkap ikan dan hasil laut lain dengan menggunakan tangguk besar. Menyondong biasanya dilakukan di sore hari sampai maghrib dengan berjalan di air dangkal di sepanjang garis pantai. Berkarang adalah kegiatan mengumpulkan hasil-hasil laut yang tertinggal di daerah pasang-surut pada saat keadaan surut. Dua kegiatan ini adalah kegiatan yang sering dilakukan di kalangan masyarakat pesisir di Pulau Bintan. Kegiatan ini memiliki nilai ekonomi dan budaya serta berpotensi memiliki kandungan nilai etnosains. Studi etnografi ini dilakukan melalui rangkaian pengamatan di beberapa tempat menyondong dan berkarang yang populer. Data tambahan diperoleh melalui wawancara. Hasil analisis data menunjukkan bahwa terdapat nilai-nilai etnosains dalam aktivitas berkarang dan menyondong ikan. Nilai etnosains yang teridentifikasi antara lain dalam bentuk nama dan pengetahuan lokal terhadap hasil-hasil laut, dalam bentuk prosedur pelaksanaan aktivitas untuk meningkatkan hasil tangkapan, dan pemahaman akan pilihan waktu pelaksanaan yang disesuaikan dengan pasang-surut air laut.

Kata Kunci: Etnosains, kearifan lokal, menyondong, berkarang, bintan.

*Penulis Korespondensi:

Alamat surel: bony@umrah.ac.id 


\section{PENDAHULUAN}

Kata ethnoscience (etnosains) bersasal dari kata ethnos (bahasa Yunani) yang berarti bangsa, dan scientia (bahasa Latin) artinya pengetahuan.Oleh sebab itu, etnosains merupakan pengetahuan yang dimiliki oleh suatu komunitas budaya.Kemudian ilmu ini mempelajari atau mengkaji sistem pengetahuan dan tipe-tipe kognitif budaya tertentu.Penekanan pada pengetahuan asli dan khas dari suatu komunitas budaya. Menurut Henrietta L. (1998) etnosains adalah cabang pengkajian budaya yang berusaha memahami bagaimana pribumi memahami alam mereka. Pribumi biasanya memiliki ideologi dan falsafah hidup yang mempengaruhi mereka mempertahankan hidup. Atas dasar ini, dapat dinyatakan bahwa etnosains merupakan salah satu bentuk etnografi baru (the new ethnography).

Pada studi tentang tingkat literasi kelautan siswa dan mahasiwa di Kepulauan Riau pada 2017, ditemukan bahwa tingkat literasi kelautan siswa dan mahasiswa berada pada kategori sangat rendah (Irawan, 2017). Hal ini mengejutkan karena hampir sebagian besar responden penelitian tersebut berasal dari daerah kepulauan. Analisis lebih lanjut menunjukkan hal ini disebabkan oleh kurangnya konten kelautan dalam mata pelajaran yang diajarkan di sekolah. Hasil observasi menunjukkan bahwa guru kesulitan mengembangkan pembelajaran yang memiliki tema dan muatan kelautan. Kesulitan ini disebabkan tidak adanya panduan bagi guru untuk menyusun indikator dan materi pembelajaran bertema kelautan di dalam naskah kurikulum. Keadaan ini mengkhawatirkan karena dapat menghambat keberhasilan pembangunan kemaritiman nasional yang memerlukan warga negara dengan literasi kelautan yang baik.

Salah satu tujuan dalam roadmap penelitian penulis adalah merumuskan framework literasi kelautan yang dapat dijadikan acuan dalam pengembangan pembelajaran di sekolah
(Irawan, 2018). Melalui framework ini, penulis ingin berkontribusi terhadap keberhasilan pembangunan kemaritiman nasional dengan mempersiapkan lulusan sekolah menengah yang ocean literated. Framework yang dikembangkan ini dapat dipandang sebagai silent curriculum yang dalam pengembangannya memerlukan beberapa input pertimbangan. Antara lain existing body of knowledge kontemporer terkait topik yang dibahas, serta sentuhan kearifan lokal dan identitas core value bangsa Indonesia sendiri.

Kesadaran akan pentingnya menemukan kembali nilai-nilai kearifan lokal dan merevitalisasinya melalui proses pendidikan adalah trend yang bermula di Jepang. Indonesia juga sebuah bangsa yang kaya akan nilai luhur dan kearifan lokal yang harus dihayati dan dilestarikan. Kemajuan IPTEK tidak lantas harus membuat bangsa Indonesia menjadi miskin identitas atau kehilangan jati diri. Banyak suku bangsa di nusantara yang telah memiliki peradaban panjang menunggu untuk digali dan direvitalisasi. Terkait bidang kemaritiman dan kelautan, komunitas melayu Kepulauan Riau adalah salah satunya. Oleh karena itu, pada fase ini, dirancang sebuah penelitian etnografi dengan tujuan untuk mengungkap dan mendokumentasikan kearifan lokal dan etnosains masyarakat melayu Kepulauan Riau.

Masyarakat melayu Kepulauan Riau adalah komunitas maritim sejati yang telah hidup berabad-abad berdampingan dengan laut. Begitu banyak pengetahuan, teknik, alat, dan ajaran terkait laut yang bisa digali dan direvitalisasi dari komunitas ini. Dengan berbagai pertimbangan tersebut, peneliti merancang sebuah penelitian kualitatif dengan pendekatan etnografi untuk menggali kearifan lokal dan etnosains masyarakat melayu Kepulauan Riau. Hasil dokumentasi penelitian ini nanti dapat menjadi sumbangan tersendiri bagi kajian etnografi melayu serta manjadi masukan yang penting dalam menyempurnakan framework literasi kelautan yang penulis kembangkan dalam roadmap 
penelitian. Framework ini esensial bagi guru untuk mengembangkan pembelajaran bertema kelautan dan kemaritiman di sekolah.

Melalui etnosains, sebenarnya peneliti budaya justru akan mampu membangun teori yang grass root dan tidak harus mengadopsi teori budaya barat yang belum tentu relevan. Penelitian etnosains terhadap fenomena budaya selalu berbasis etno dan atau folk.Kehadiran etnosains, menurut Spradley(2001) memang akan memberi angin segar pada penelitian budaya. Meskipun hal demikian bukan hal yang baru, karena sebelumnya telah mengenal verstehen (pemahaman), namun tetap memberi wajah baru bagi penelitian budaya.Oleh karena, memang banyak peneliti budaya yang secara sistematis memanfaatkan kajian etnosains.Memang belum ada kesamaan pendapat mengenai istilah etnosains dikalangan peneliti budaya.Istilah ini ada yang menyebut cognitif anthropology, ethnographic semantics, dan descriptive semantics (Spradley, 2001).Berbagai istilah ini muncul karena masing-masing ahli memberikan penekanan berbeda, namun hakikatnya adalah ingin mencari tingkat ilmiah kajian budaya.

Setiap masyarakat mengalami pertumbuhan dan perkembangan akibat kebutuhan yang berubah dari zaman ke zaman.Dalam perkembangan itu terjadi berbagai proses pemecahan masalah demi kehidupan yang lebih baik dan sejahtera melalui teknologi. Perkembangan ilmu pengetahuan dan teknologi tak lepas dari dampak positif dan negative. Di satu sisi penerapan ilmu pengetahuan dan teknologi telah melahirkan berbagai inovasi untuk meninkatkan kesejahteran hidup manusia, namun di sisi lainpenerapan ilmu pengetahuan dan teknologi juga telah mengeksploitasi kekayaan alam untuk mengejar produksi tanpa mempertimbangkan kelangsungan hidup jangka panjang seperti yang terjadi pada dampak rusaknya lingkungan alam yang mengakibatkan berbagai bencana alam seperti kekeringan berkepanjangan, banjir, kebakaran hutan, polusi udara yang kesemuanya hanya menghasilkan kesengsaraan rakyat banyak.

Lingkungan, baik fisik maupun sosial-budaya dapat memberikan kontribusi tertentu pada pengalaman belajar siswa.Pengalaman tersebut dapat berupa pola pikir (ranah kognitif), pola sikap (ranah afektif), maupun pola perilaku (ranah psikomotorik).Solomon (dalam Baker, et al, 1995) menyatakan konsep-konsep sains yang dikembangkan di sekoiah tidak berjalan mulus karena dipengaruhi kuat oleh faktorfaktor sosial, khususnya pengetahuan intuitif tentang dunia lingkungannya (life-word). Pengetahuan tersebut dibangun selama siswa masih kanak-kanak yang disosialisasikan dan dienkulturisasi oleh orang lain (seperti orang tua dan teman sebaya). Ogawa (2002) menyatakan salah satu sains intuitif adalah sains sosial atau budaya (culture or social science) atau disebut juga dengan sains asli (indigenous science). Snively \& Corsiglia (2001 :6) menyatakan bahwa sains asli berkaitan dengan pengetahuan sains yang diperolehnya melalui budaya oral di tempat yang sudah lama ditempatinya. Pengetahuan ini sudah merupakan bagian budaya mereka yang diperoleh dari pandangannya tentang alam semesta yang relatif diyakini oleh komunitas masyarakat tersebut.Namun, sampai saat ini sains asli yang merupakan subbudaya dari kelompok masyarakat, kurang disadari dan kurang mendapat perhatian dari para pakar pendidikan sains maupun guru-guru sains di Indonesia.

Baker, et al (1995) menyatakan, bahwa jika pembelajaran sains di sekolah tidak memperhatikan budaya anak, maka konsekuensinya siswa akan menolak atau menerima hanya sebagian konsep-konsep sains yang dikembangkan dalam pcmbelajaran. Stanley \& Brickhouse (2001) menyarankan agar pembelajaran sains di sekolah menyeimbangkan antara sains Barat (sa ins normal, sains yang dipelajari dalam kelas) dengan sains asli (sains tradisional) dengan menggunakan pendekatan lintas budaya (cross-culture). Pendapat senada juga 
dikemukakan oleh Cobern dan Aikenhead (1996: 4), yang menyatakan jika subkultur sains modern yang diajarkan di sekolah harmonis dengan subkultur kehidupan seharihari siswa, pengajaran sains akan berkecenderungan memperkuat pandangan siswa tentang alam semesta, dan hasilnya adalah enculturation.

\section{METODE PENELITIAN}

Penelitian ini adalah penelitian etnografi dengan tujuan untuk menginventarisasi dan mendokumentasikan kearifan lokal dan etnosains masyarakat melayu Kepulauan Riau yang berhubungan dengan laut. Metode yang dilakukan mengadopsi pendekatan naturalistik dimana peneliti sebagai observer turun langsung membaur dengan komunitas yang menjadi subjek penelitian. Menurut Fraenkel dan Wallen (2009), metode ini memungkinkan observer untuk memperoleh gambaran yang paling nyata terhadap sasaran yang ingin diamati. Dengan pendekatan naturalistik, penghalang antara observer dengan subjek penelitian dapat dihilangkan sehingga mengurangi bias dan unnatural occurance pada set pengamatan.

Pengumpulan data dilakukan dengan teknik indepth interview, observasi, dan dokumentasi. Instrumen yang digunakan adalah panduan wawancara, inventori prediksi etnosains, lembar observasi, serta catatan anekdot. Instrumen tersebut dirancang untuk menghimpun data dari semua aspek yang potensial terkait keberadaan etnosains dan kearifan lokal komunitas masyarakat yang diamati.

Subjek penelitian adalah komunitas masyarakat yang hidup di pesisir Pulau Bintan, Data mentah yang terkumpul kemudian ditransliterasi menjadi bentuk tertulis yang dapat disajikan secara ilmiah.

\section{HASIL DAN PEMBAHASAN}

A. Nilai Etnosains dalam Kegiatan Berkarang

Aktifitas berkarang dilakukan oleh berbagai kalangan masyarakat pesisir. Baik yang berprofesi asli sebagai nelayan, maupun anggota masyrakat lain yang datang berkarang sekadar untuk kegiatan rekreasional. Apapun motivasi awalnya, berkarang tetap memberikan nilai ekonomi bagi pelakunya. Sehingga berkarang menjadi kegiatan yang populer di masyarakat Bintan.

Berkarang biasanya dilakukan pada sore hari atau di pagi hari pada saat keadaan laut surut. Hal ini terkait dengan tipe pasang surut di perairan Kepulauan Riau yang bertipe diurnal (Irawan, 2016). Pada saat keadaan surut, berbagai biota laut akan terdampar pada daerah intertidal, antara lain ikan, kepiting, udang, teripang, timun laut, bintang laut, dll. Spesies yang terdampar inilah yang menjadi target berkarang oleh masyarakat. Hasil dari berkarang dapat dimakan sendiri atau dijual.

Berdasarkan observasi dan wawancara dapat dirumuskan beberapa nilai etnosains dalam kegiatan berkarang, disajikan dalam poin-poin sebagai berikut:

1. Pengetahuan tentang waktu pasang dan surut lokal

Kegiatan berkarang hanya dapat dilakukan pada saat laut dalam keadaan surut. Sebagian besar masyarakat yang berkarang memiliki pengetahuan tentang jadwal pasang surut harian di lokasi pantai tempat mereka berkarang. Mereka dapat memperkirakan waktu pasang dan surut yang pas untuk kegiatan berkarang yang biasa dilakukan saat pagi dan sore hari. Mereka juga memahami pergeseran waktu pasang dan surut tergantung posisi bulan yang dihitung berdasarkan penanggalan hijriah. 
2. Pengetahuan dalam bentuk nama lokal spesies laut hasil tangkapan

Masyarakat yang sering turun berkarang memiliki pengetahuan lokal tentang biotabiota laut hasil tangkapan mereka. Mereka memiliki nama daerah yang khas untuk berbagai spesies yang sering dijumpai.

3. Pengetahuan umum tentang spesiesspesies yang sering dijumpai.

Pada saat surut, banyak sekali biota laut yang tertinggal di daerah intertidal. Diantara banyak banyak biota laut tersebut, ada yang bernilai ekonomi, dapat dijadikan bahan pangan, ada juga yang tidak bermanfaat untuk dipungut. Bahkan ada juga spesies yang berbahaya seperti lepu, ubur-ubur api, kerong tekstil, dll. Masyarakat yang sering turun berkarang memiliki wawasan tentang hal-hal tersebut. Mereka telah memahami spesies mana yang boleh diambil, dan spesies mana yang tidak layak diambil, bahkan mengetahui spesies yang tidak boleh disentuh. Tidak jarang dalam berkarang masyarakat membawa serta anakanak mereka. Dalam kondisi ini, berkarang juga memiliki nilai edukasi dan pewarisan pengetahuan lokal dari generasi ke generasi.

\section{B. Nilai Etnosains dalam Kegiatan Menyondong Ikan}

Menyondong adalah kegiatan menangkap hasil laut dengan menggunakan tangguk besar sambil berjalan di air dangkal di sepanjang garis pantai. Menyondong adalah kegiatan yang lebih mengarah pada motif ekonomi, karena hanya dilakukan oleh warga yang berprofesi sebagai nelayan dan menggunakan peralatan dan teknik khusus. Menyondong ikan biasanya dilakukan di sore hari sampai matahari terbenam.

Aktivitas menyondong sarat akan muatan etnosains. Berikut adalah beberapa poin yang dirumuskan sebagai hasil dari penelitian ini:
1. Peralatan tangguk yang digunakan

Menyondong ikan dilakukan dengan menggunakan tangguk besar yang bingkainya terbuat dari kayu atau rotan. Pada bingkai ini dipasang jaring. Radius tangguk bisa mencapai $1.75 \mathrm{~m}$ sampai dengan $2 \mathrm{~m}$. Tangguk ini dipilih untuk memaksimalkan hasil tangkapan dan tetap bisa digunakan sambil berjalan.

\section{Pemilihan waktu menyondong}

Menyondong dilakukan pada sore hari sampai matahari terbenam sebagai aktifitas ekonomi tambahan masyarakat pesisir. Waktu sore juga dipilih karena target tangkapan banyak berada di perairan dangkal. Sehingga hasil tangkapan menjadi lebih banyak. Hal ini sesuai dengan aktivitas dan migrasi harian hewan laut (Niyabkken, 2003). Hal ini menunjukkan pengetahuan masyarakat terhadap keadaan laut disekitarnya.

\section{Pemilihan lokasi menyondong}

Menyondong cocok dilakukan pada pantai yang landai dan tidak memiliki banyak kontur karang. Substrat dalam bentuk lumpur atau pasir berlumpur juga lebih disukai oleh para penyondong. Hal ini sesuai dengan keadan beberapa pantai di pesisir Bintan yang memiliki substrat lumpur dan pasir berlumpur (Irawan, 2016). Dalam hal ini penyondong memilih lokasi menyondong sesuai pengetahuan mereka terhadap keadaan pantai di sekitar mereka

\section{KESIMPULAN DAN SARAN}

Masyarakat Bintan memiliki banyak kearifan lokal dan etnosains yang menarik untuk dikaji secara ilmiah. Aktivitas berkarang dan menyondong memiliki kandungan nilai etnosains yang dapat dihubungkan dengan sains biologi modern. Aktivitas ini selain bernilai ekonomi juga memiliki nilai rekreasional dan edukasi bagi anggota keluarga. 


\section{UCAPAN TERIMA KASIH}

Penelitian ini terselenggara atas pembiayaan hibah penelitian dosen pemula (PDP) yang diberikan oleh Direktorat Penelitian dan Pengabdian Kepada Masyarakat (DRPM) Kementerian Riset Teknologi dan Pendidikan Tinggi. Penulis menyampaikan terima kasih atas dukungan yang diberikan.

\section{DAFTAR PUSTAKA}

Aikenhead, G \& O.J. Jegede (1999). CrossCultural Science Education: A Cognitive Explanation of a Cultural Phenomenon. Joumal of Research in Science Teaching. Vol 36, pp. 269-287.

Anderson L.W., dan Krathwol, D.R.., 2010. A Taxonomy for Learning, Teaching, and Assessing: A revision of Bloom's Taxonomy of Education Objectives. New York: Addison Wesley Longman

Arifin, Zainal. 2012.Konsep dan Model Pengembangan Kurikulum. Bandung: Remaja Rosdakarya

BPS. 2018. Demografi Provinsi Kepulauan Riau. Diakses 29 Juli 2018. (www.bps.go.id)

Chou, Cynthia. 2008. Research Trends on Southeast Asian Sea Nomads. Indonesian Circle 67 (Nov 2008)

Cobern,W.W.\&Aikenhead,G.S. (1996). Cultural Aspects of Learning Science.SLCSP Working paper \#121.http://www.wmich.edu/slcsp.121.htm lJune 2002

Henrietta L. Moore, 1998. Feminisme Dan Antropologi (Penerjemah: Tim Proyek Studi Jender dan Pembangunan FISIP UI). Jakarta: Penerbit Obor.

Ifediora et. al., 2017. Perception and Patronage of Foreign Value in Developin Countries. International Journal of Economics and Management Vol. V Issue 12 2017. UK

Irawan. Bony. 2018. Framework Literasi Kelautan Sebagai Acuan Pembelajaran Sains di Negara Maritim. Pedagogi ahayati, Vol 2 $\begin{array}{llll}\text { No } & 1 & \text { Tahun } & 2018 .\end{array}$ (www.ojs.umrah.ac.id/index.php/pedagogi hayati (DOI : https://doi.org/10.31629/pedag.hayati.v2i1. $\underline{413}$ )

Irawan, Bony. 2017. Profil Literasi Kelautan Mahasiswa Kepulauan Riau. Jurnal
KIPRAH Vol VI. No. 1 2017. UMRAH Press.

Irawan, Bony. (2016). Buku Ajar Biologi Laut. Tanjungpinang: UMRAH Press

Moore, Henrietta L., 1998. Feminisme Dan Antropologi (Penerjemah: Tim Proyek Studi Jender dan Pembangunan FISIP UI). Jakarta: Penerbit Obor.

Malik, A. 2017. Indeks Budi Pekerti Pribadi Dalam Karya Raja Ali Haji. Jurnal KIPRAH Vol 5. No.2 Tahun 2017. Indonesia. (ojs.umrah.ac.id/kiprah)

Marnelly, Romi T., 2017. The Local Wisdom of Malay Society of Coastal Area in Using Natural Resource. Proceeding, AASIC Conference 2017

OECD. 2016. "PISA (Programme for International Assessment)." Diakses pada 10 Agustus 2018

(http://www.oecd.org/pisa/aboutpisa/)

Ogawa,M. (2002). Science as the Culture of Scientist: How to Cope with Scientism http://sce6938-01.fsll.edu/ogawa.html.

Stanley,W.B\& N.W. Brickhouse. (2001). The Multicultural Question Revisited. Science Education.Vol 85 (I).Pp.35-48.

Zais, Robert. S. 2008. Curriculum Principles and Foundations . New York: Harper and Row Publisher 